\title{
A Study of Lightweight Door Hinges of Commercial Vehicles Using Aluminum Instead of Steel for Sustainable Transportation
}

\author{
Tufan Gürkan Yılmaz ${ }^{1}$, Mustafa Tüfekçi ${ }^{2}$ and Fatih Karpat ${ }^{1, *}$ \\ 1 Department of Mechanical Engineering, Uludag University, Bursa 16059, Turkey; \\ tufanyilmaz@uludag.edu.tr \\ 2 OSB Yeşil Cd. No 2616159 Nilüfer, Bursa 16140, Turkey; mstafatufekci@gmail.com \\ * Correspondence: karpat@uludag.edu.tr; Tel.: +90-224-294-1930
}

Received: 1 July 2017; Accepted: 15 September 2017; Published: 25 September 2017

\begin{abstract}
Recently, lightweight design concepts have come into prominence for vehicle industry, especially for economic and environmental sustainability. Vehicle manufacturers have investigated new material usage to reduce fuel consumption and air pollution as increasing concerns. On the other hand, new legal obligations and global competition have accelerated this research and development process. Designing components with low-density materials is one the most common methods for reducing $\mathrm{CO}_{2}$ emissions. Among these materials, aluminum alloys stand out due to their adequate mechanical properties and specific strength. In this work, the study of lightening door hinges of a commercial vehicle is presented. To reduce the weight of vehicle door hinge, three different aluminum alloys are tried out and compared with steel. Finite element analysis (FEA) and experiments are conducted to determine if the safety requirements are fulfilled or not. According to results with an Al7075-T73 alloy, the weight of door hinge can be reduced by approximately $65 \%$. Stress and strain values are suitable for FMVSS0206 standards. Additionally, it passed the corrosion test.
\end{abstract}

Keywords: lightweight; aluminum alloys; door hinge

\section{Introduction}

Today, with decreasing energy resources and increasing global warming, reducing energy consumption and total $\mathrm{CO}_{2}$ emissions has become the most important priority in view of environmental and economic sustainability in the vehicle industry. To ensure this, it is important that products and processes be designed with using lower weight, energy, and time. Within this context, investigating of usage of lightweight materials has become inevitable. It is predicted that global energy demand will increase by 53\% between 2008 and 2035. The second largest sector in view of energy consumption, transportation has a great role on this increase. One-third of energy consumption originates from transportation in the European Union. Also, $10 \%$ of $\mathrm{CO}_{2}$ emissions directly arise from road transport which is the largest sector of transportation. It is evaluated that this rate will be nearly doubled by 2050 if radical precautions are not taken [1,2].

There are several approaches such as using alternative fuel systems, reducing the size of the engine, and decreasing the structural weight of the vehicle to ensure vehicle energy efficiency. Among these, weight reduction is one of the most efficient ways for improving sustainable design. Since nearly $75 \%$ of fuel consumption of the vehicle is related to weight. Helms and Lambrecht [3] stated that $100 \mathrm{~kg}$ weight reduction means $0.4 \mathrm{~L}$ less fuel usage per $100 \mathrm{~km}$ distance. Consequently, it ensures $10 \mathrm{~g}$ lower $\mathrm{CO}_{2}$ emissions. Although these values look small, they are highly significant since 18 million vehicles are manufactured per year in Europe. Ungureanu et al. [4] specified that the weight of a vehicle is the valid parameter as it is directly related to breaking resistance and acceleration forces. 
Kobayashi et al. [5] studied the relationship between weight and $\mathrm{CO}_{2}$ emissions. They concluded that a $10 \%$ decrease in vehicle weight ensures $6-8 \%$ lower fuel usage.

\subsection{Aluminum Usage for Weight Reduction}

In vehicle design, usage of materials with low density is one of the most preferred methods for decreasing weight. Aluminum is a lightweight material with several advantages. It is one-third of steel's density. It has high corrosion resistance with proper heat treatment. Mechanical properties of some aluminum alloys could compete even with steel. According to a study from the Aluminum Union of Europe, aluminum is lighter than structural steel by $60 \%$, and it is lighter than high strength steel by $40 \%$, providing that they have same strength value. For same hardness values, aluminum is lighter than structural steel by $45 \%$ [6]. As well as being lightweight, the requirements of lower energy consumption, high recyclability, and easy manufacturability, aluminum usage in vehicles has been growing in the last decade. Cheah et al. [7] investigated the effects of the material on the weight of the vehicle. By replacing cast iron components with aluminum, vehicle weight could be decreased by up to $600 \mathrm{~kg}$. Bandivadekar et al. [8] declared that using aluminum instead of traditional materials in vehicle ensures $30 \%$ weight reduction and results in $18-24 \%$ lower $\mathrm{CO}_{2}$ emissions.

\subsection{Regulations for Door Hinges of Commercial Vehicles}

Vehicle door hinges are the main components for the safety of the driver and the passengers. It links the door to the vehicle body. During any crash, it is mandatory that door must not separate from the body. On the other hand, long life is one of the expectations from door hinges. For these reasons, door hinges have to be meet safety regulations which are set by the FMVSS0206 standard. These regulations are:

In strength testing, force is applied bi-directionally from the $\mathrm{X}$ and $\mathrm{Y}$ axis of the vehicle on the door hinge. According to the hinge strength test, the door hinge must not be broken, and stress inflicted on the hinge must not exceed the ultimate tensile strength of the material of the hinge.

With the door drop off test, the door is placed in the open position and the door is subjected to its weight. The elastic deflection of the door which is measured at the lock point of the door must not be higher than a specified limit value.

The door SAG test is quite similar to the drop off test except that extra force is applied to the lock point of the door. In this test, two values have to be obtained. First, is the elastic deformation that occurs when additional force is applied to the door and the second is the plastic deformation after the load is removed.

With the wind gust test, when the door is its fully open position, it is subjected to extra load in its opening direction. In this situation, the stretch angle must not exceed the determined limit value. Besides, the stress must not be higher than the yield strength of hinge material.

The door durability test, which is critical for evaluating service life of the product, is conducted in standard room conditions. In this test, the door is opened and closed a specified number of times. After the test, no damage should be detected.

Corrosion testing is conducted in a salt fog chamber for specified hours. At the end of this trial, no corrosion has to be detected on hinge surface.

It has been determined that the strength and wind gust test are the most critical tests on hinges as the demands of these requirements are stricter than the others. Hinge designs which pass these standards are deemed safe [9].

\subsection{Conventional Door Hinge}

As a critical vehicle component the door hinge links vehicle body to the door. Their primary duties are to lock and unlock the car door. The second one is to protect body-door connection, especially during an accident. The conventional door hinges consist of four parts, a fixed part of the hinge on the vehicle body, a mobile part of the hinge on a door, a pin to link fixed and mobile components and 
a plastic stopper to reduce the noise of open-close of the door. Traditionally, these components are generated from structural steel with a forging process. In Figure 1, the components of door hinge for the commercial vehicle are illustrated.

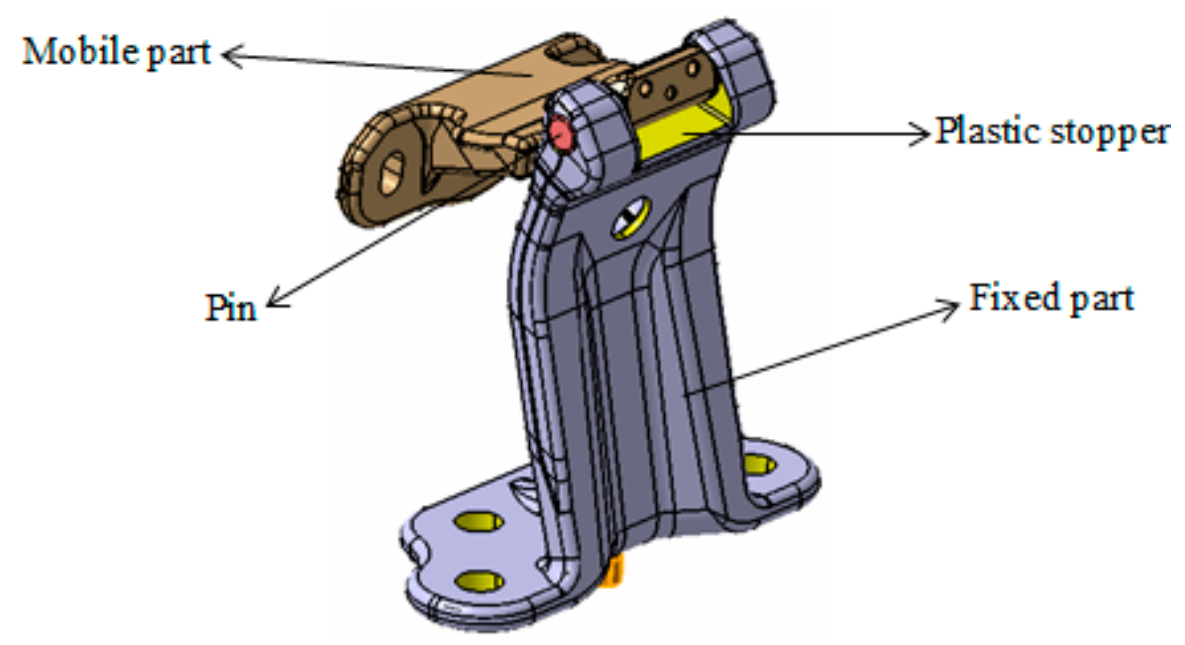

Figure 1. Conventional commercial vehicle door hinge.

\subsection{Motivation and Objectives}

Public transportation with commercial vehicles has been growing swiftly in the European Union. In 2010, EU citizens traveled via public transit vehicles nearly 1000 miles per capita. For this reason, reducing the total weight of commercial vehicles has great importance. Traditional commercial vehicles have four to six door hinges. The overall weight of door hinge is assumed $2-3 \mathrm{~kg}$ with conventional steel material. If steel material is replaced with proper aluminum alloy, the weight of hinge can be decreased to $50 \%$ of its current weight approximately. This means $4-9 \mathrm{~kg}$ weight reduction per vehicle. This decrease could appear small when comparing total weight of a vehicle. However, in fact, when the production volume of this type of vehicle $(150,000$ / per annum) is taken into account, tons of materials could be saved. This savings ensures thousands of kilograms lower $\mathrm{CO}_{2}$ emissions. Besides, it also decreases the amount of wastage during the manufacturing process. With these statements, it is seen that the weight reduction of door hinges is quite important. Therefore, using aluminum in door hinges contributes to the sustainability of transportation.

In this study, the lightweight study is realized with using aluminum alloy in commercial vehicle door hinge design. To investigate convenience of usage of aluminum, FEA which simulates safety regulations is conducted for different alloys. AA7075-T73 is found more suitable according to FEA results. Then, the prototype of an AA7075-T73 door hinge is manufactured with forging for experiments. It passed all tests substantially.

\section{Materials and Methods}

Finite element analysis is a highly reliable engineering approach and valid tool for product development. It reduces time spent on design and validation processes. Thus, the cost of design decreases. It has several advantages such as analyzing complex geometry, anisotropic and nonlinear material, etc. The accuracy of results of finite element analysis depends on using real mechanical values of material, using proper boundary conditions, and meshing smoothness. For anisotropic material, the Poisson ratio has to be defined. For meshing, better results are obtained with tetra shape elements rather than triangle shaped ones. In this study, finite element analyses are conducted on commercial vehicle door hinges with steel and three different aluminum alloys. Hypermesh is used for meshing and model is solved in Radioss. Mechanical properties of candidate materials are illustrated in Table 1. 
Table 1. Mechanical properties of candidate hinge materials.

\begin{tabular}{ccccc}
\hline Mechanical Properties & S355J0 & A16082 & A16262 & A17075 \\
\hline Elasticity modulus (MPa) & 210,000 & 68,000 & 68,000 & 72,000 \\
Yield strength (MPa) & 355 & 290 & 379 & 435 \\
Poisson ratio & 0.3 & 0.33 & 0.33 & 0.33 \\
Ultimate tensile strength (MPa) & 554 & 320 & 400 & 505 \\
\hline
\end{tabular}

In the present work, hinge strength and wind gust tests are taken into account for FEA and experiments since they are more critical than the other tests. After these tests, durability and corrosion tests are conducted finally. For strength test, $F_{1}=19,800 \mathrm{~N}$ is applied on $X$ direction, and $F_{2}=15,800 \mathrm{~N}$ is applied on $Y$ direction, simultaneously. These forces are extremely high to simulate any severe crash conditions. The door has its closed position in this test. Figure 2 illustrates the loading conditions and directions of the strength test.

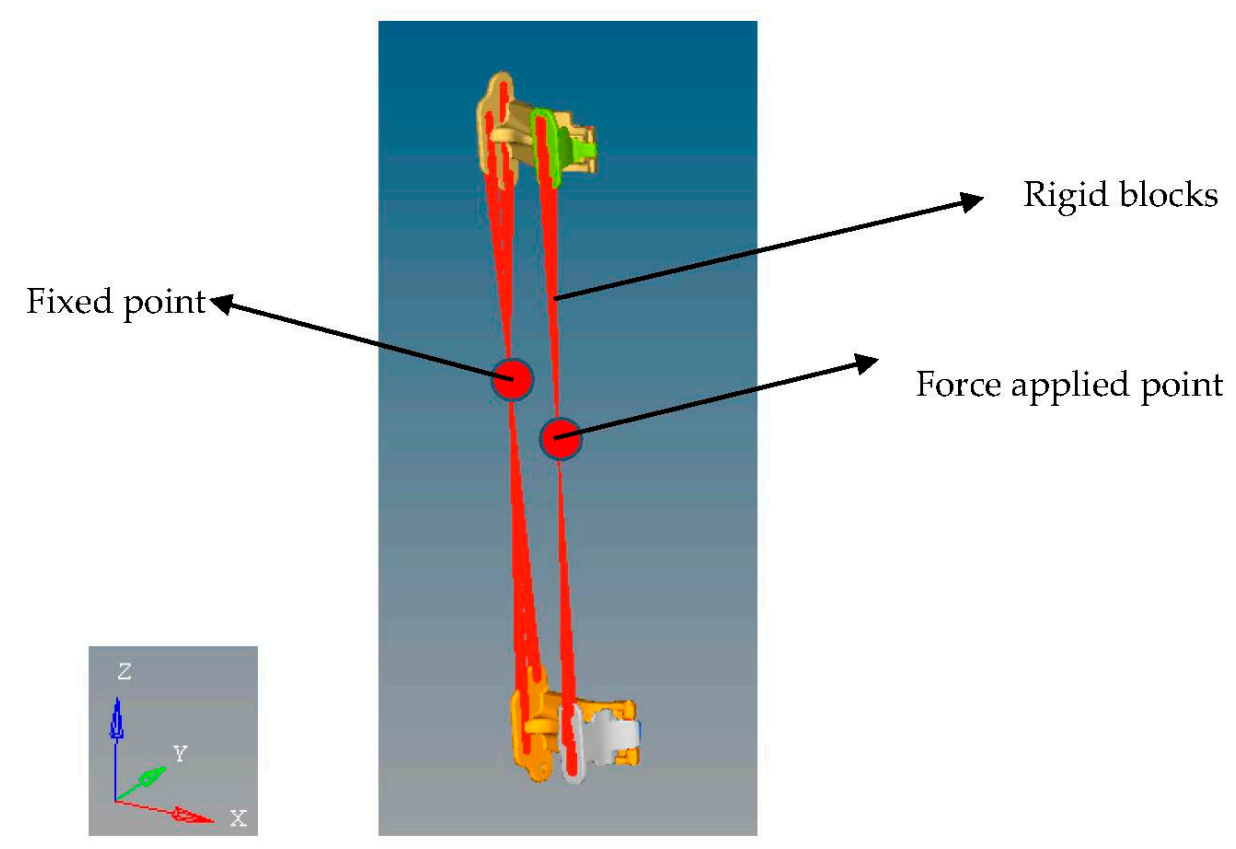

Figure 2. Loading conditions of hinge strength test.

The wind gust test is the hardest regulation of door hinges. It simulates the door being subjected to a heavy wind when it is in a fully opened position. $F_{3}=1000 \mathrm{~N}$ is applied on lock point of the door. In this situation, the maximum stretch angle has to be lower than $5^{\circ}$. In Figure 3 , the loading conditions of wind gust test are presented.

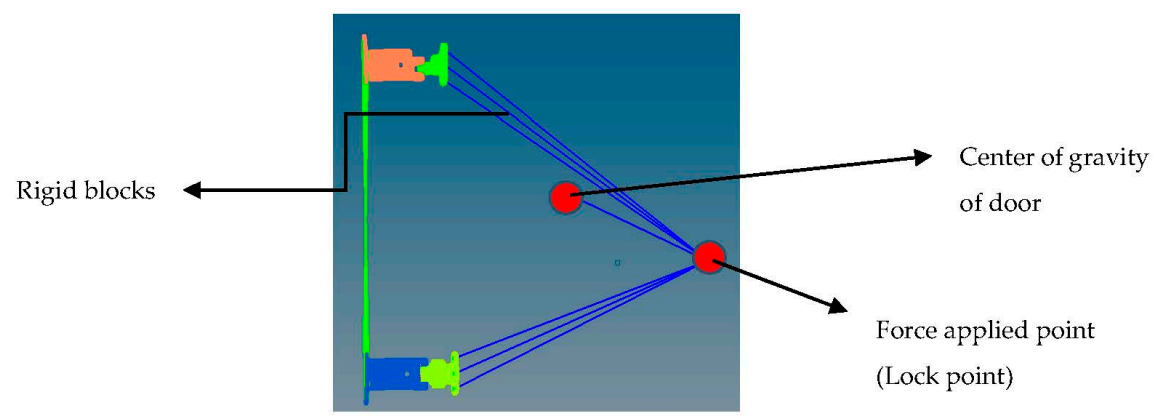

Figure 3. Loading conditions of wind gust test. 
The flowchart of this study is presented in Figure 4.

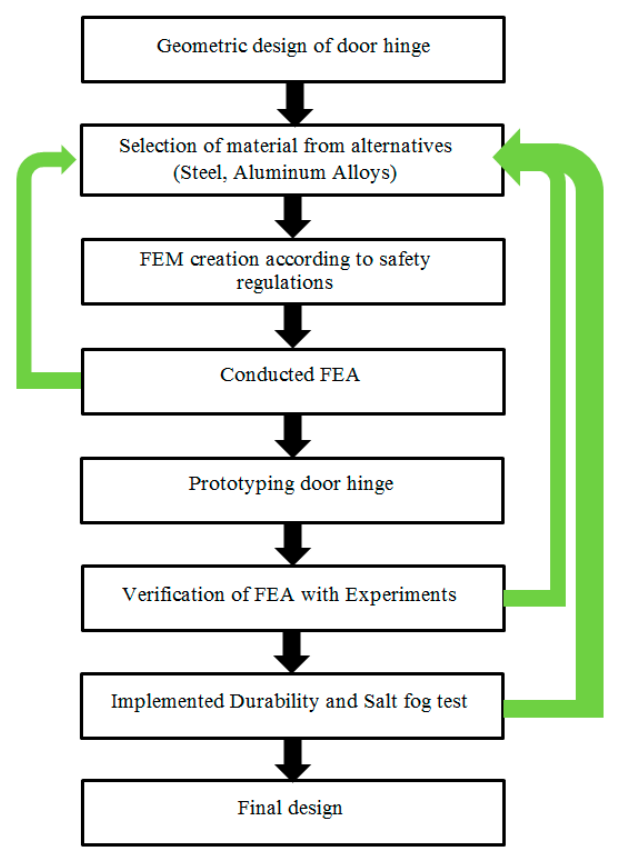

Figure 4. Flowchart of lightweight process.

\section{Results and Discussion}

In this paper, the door hinge of a commercial vehicle is analyzed for weight reduction under safety regulations. The weight of hinge decreases with using aluminum alloys by $65 \%$ when comparing steel usage. However, 6082 and 6262 alloys did not pass the wind gust regulation while 7075 passed both tests. FEA results are validated with experiments.

According to the hinge strength test, stress and strain values on hinge are suitable for steel material. The maximum von Mises stress of nearly $373 \mathrm{MPa}$ occurs on the pin hole of the fixed hinge for the $\mathrm{X}$ direction and, for the $\mathrm{Y}$ direction, the maximum value is approximately $364 \mathrm{MPa}$. In Figure 5, stress distribution on the hinge is presented.

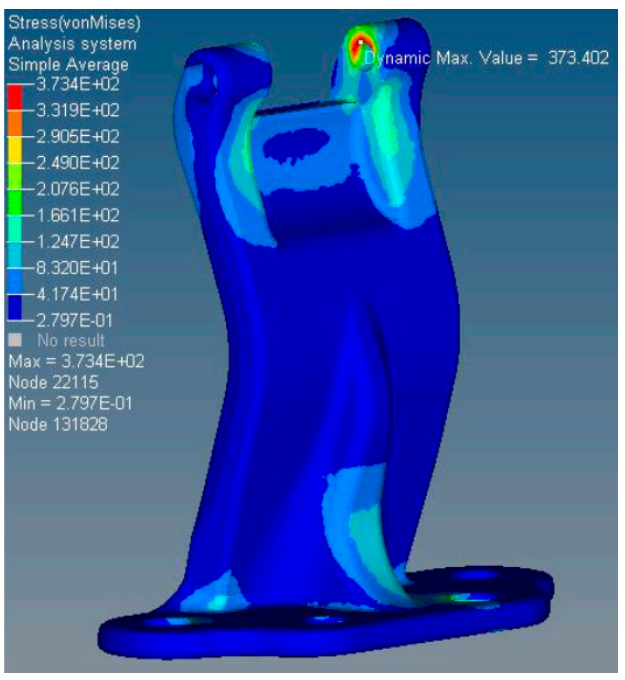

(a)

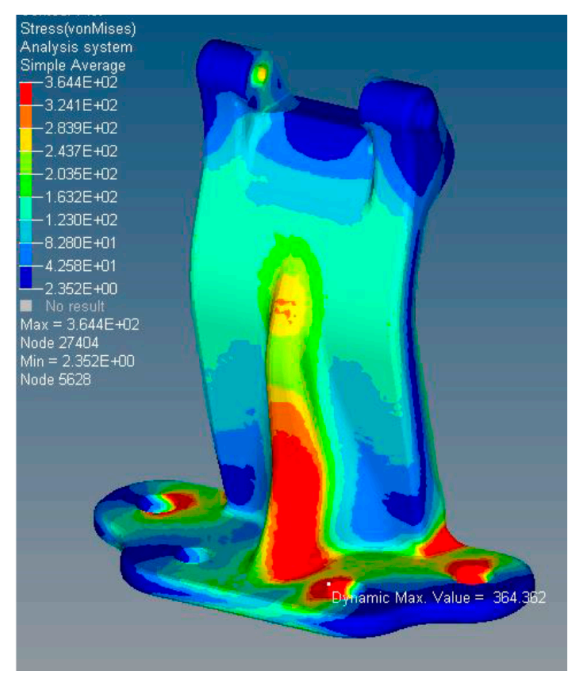

(b)

Figure 5. (a) Stress distribution in $\mathrm{X}$ direction for hinge; (b) stress distribution in $\mathrm{Y}$ direction for hinge. 
For pin, the average stress value is $600 \mathrm{MPa}$ for $\mathrm{X}$ direction and $479 \mathrm{MPa}$ for $\mathrm{Y}$ direction. The stress occurring on the pin is presented in Figure 6.

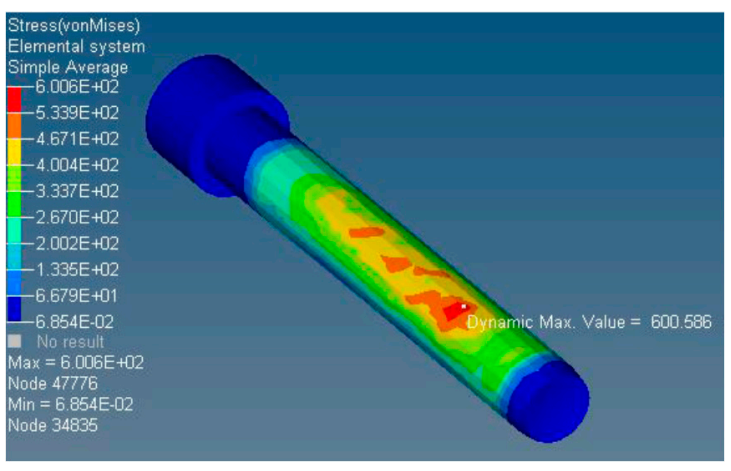

(a)

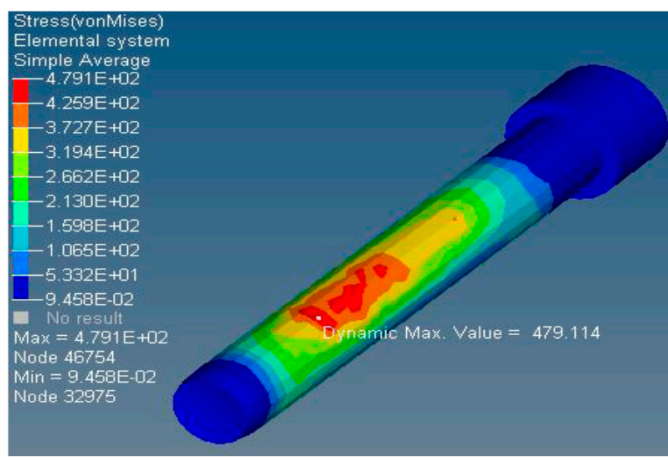

(b)

Figure 6. (a) Stress distribution in $\mathrm{X}$ direction for pin; (b) stress distribution in $\mathrm{Y}$ direction for pin.

The hinge structure with Al6082 and 6262 met the requirement of hinge strength test according to results. In Table 2, the maximum stress values are presented.

Table 2. The maximum stress occurring in aluminum alloys in the $X$ and $Y$ directions.

\begin{tabular}{lcc}
\hline & A16082 & A16262 \\
\hline Maximum stress (MPa) (X) & 295 & 382 \\
Maximum stress (MPa) (Y) & 291 & 380 \\
\hline
\end{tabular}

These values are acceptable and do not lead to any broken since they are lower than ultimate tensile stress.

For wind gust test, the maximum stress is nearly $357 \mathrm{MPa}$ and occurred again on pin hole of the hinge when using steel. On the other hand, the stress value on the pin is $410 \mathrm{MPa}$ which does not cause any breakage risk. Another requirement is stretch angle value on the door which is related to a displacement of lock point. The displacement value is $29.1 \mathrm{~mm}$. Stretch angle is $2.15^{\circ}$, and this value could be found via cosine theorem. In Figure 7, the displacement and angle are shown.

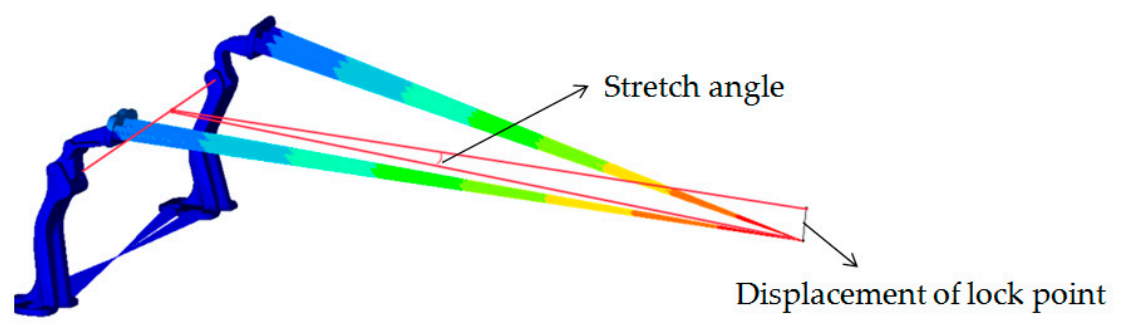

Figure 7. Stretch angle occurring in the wind gust test with steel.

With the Al6262, the displacement of door lock point is 90.308 which is not met the fourth regulation. After that, 7075 alloys are analyzed. Although the better result is achieved, the stretch angle exceeds the limit value for wind gust test. In Table 3, displacement and angle values are presented. 
Table 3. Stretch angle and displacement occurred for aluminum alloys in wind gust test.

\begin{tabular}{ccc}
\hline & A16262 & Al7075 \\
\hline Displacement $(\mathrm{mm})$ & 90.308 & 87.369 \\
Stretch angle $\left(^{\circ}\right)$ & 6.91 & 5.99 \\
\hline
\end{tabular}

Due to the elasticity modulus of aluminum, displacement values are higher when comparing steel. When the door is in a fully opened position, mobile and fixed component of hinge have contact with plastic stopper. In the current design, this stopper is only on the fixed part. In the new concept, a plastic stopper is added on the mobile component to decrease the stretch angle. On the other hand, the design is slightly changed for manufacturability of aluminum.

In Figure 8, the new design of the hinge is presented.

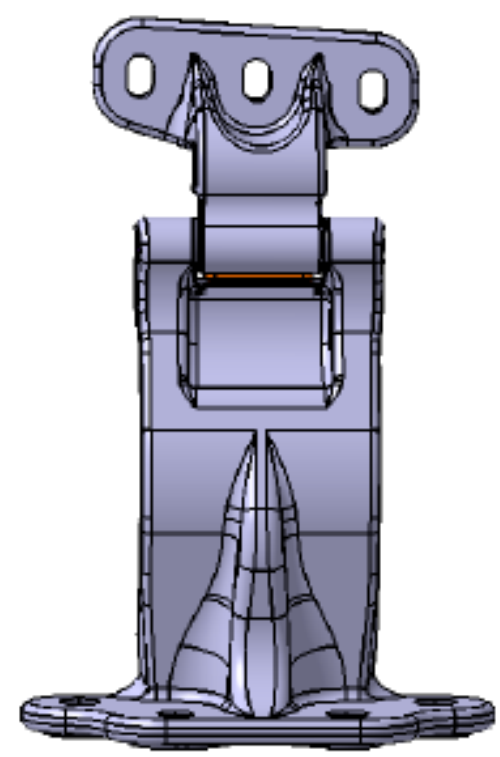

Figure 8. New design with extra plastic stopper.

The wind gust test applied to the new design. By adding one more plastic stopper and improving the geometry, the displacement value is decreased. In Figure 9, results of the fourth test for the new design are presented.

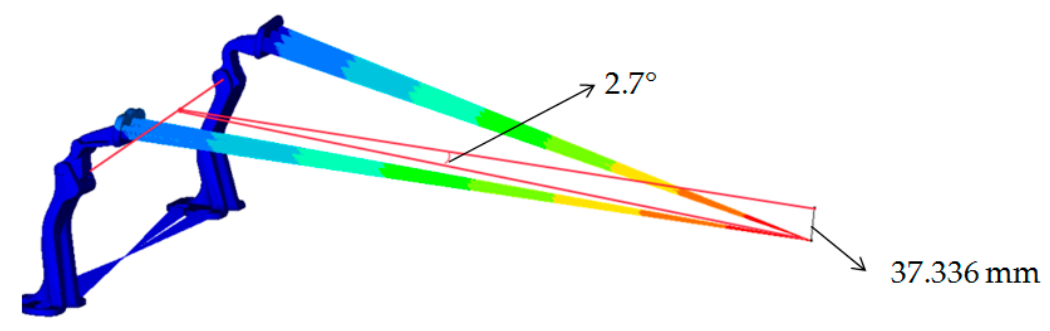

Figure 9. Result of the fourth test with new design.

After the FEA results are compatible with regulations, the prototype of the hinge with Al7075-T73 alloy is generated for experiments. Its chemical composition of this alloy is $89 \% \mathrm{Al}, 5.5 \% \mathrm{Zn}, 1.5 \% \mathrm{Cu}$, $2.1 \% \mathrm{Mg}, 0.5 \% \mathrm{Fe}, 0.4 \% \mathrm{Si}, 0.3 \% \mathrm{Mn}, 0.2 \% \mathrm{Cr}$, and the others elements are split among the remainder. The aluminum door hinge was manufactured using a close-die hot forging $\left(400{ }^{\circ} \mathrm{C}\right)$ process on a screw press with a 1500 ton capacity as the forging machine. The process was fulfilled with four phases 
which are bending, pre-formed forging, trimming, and finishing. Pin and fastener holes are generated with machining before heat treatment.

In Figure 10, a phase of manufacturing and the prototype of door hinge are illustrated. For verification of FEA, prototype hinges are objected to bench tests.

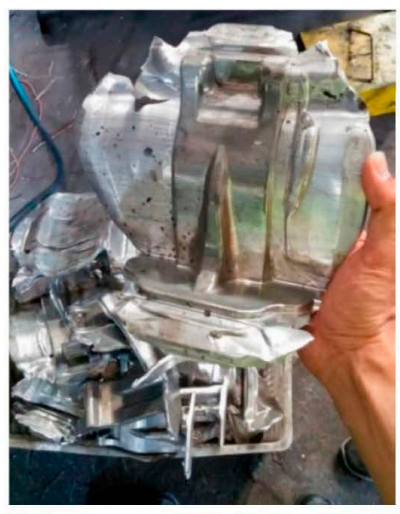

(a)

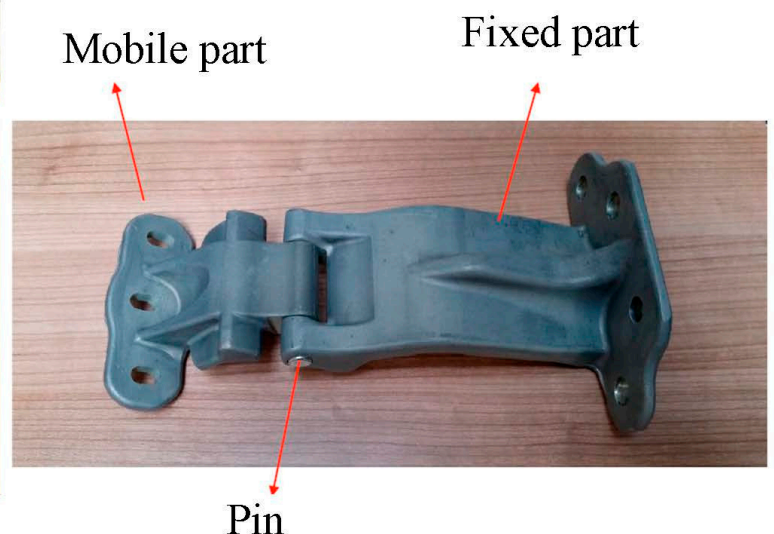

(b)

Figure 10. (a) A phase of manufacturing; (b) door hinge with Al7075 alloy.

In Figure 11, the views of test benches are illustrated.

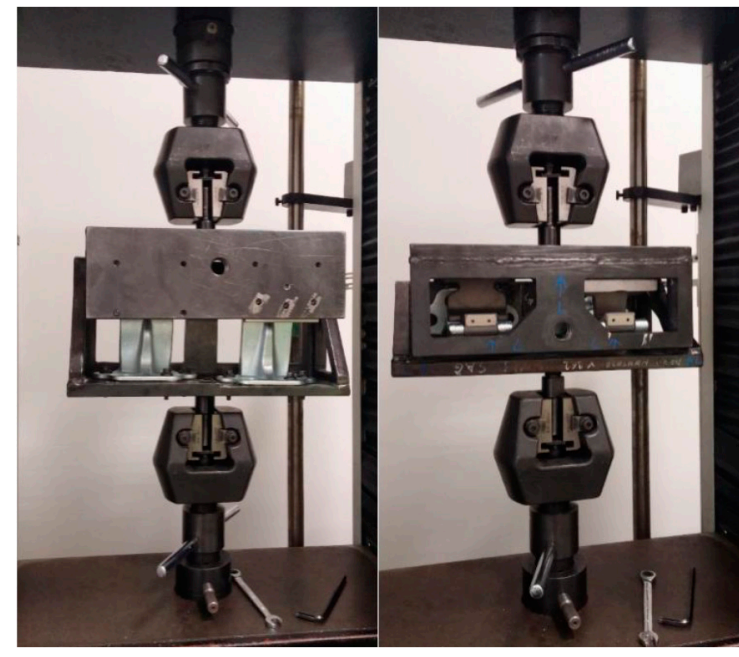

(a)

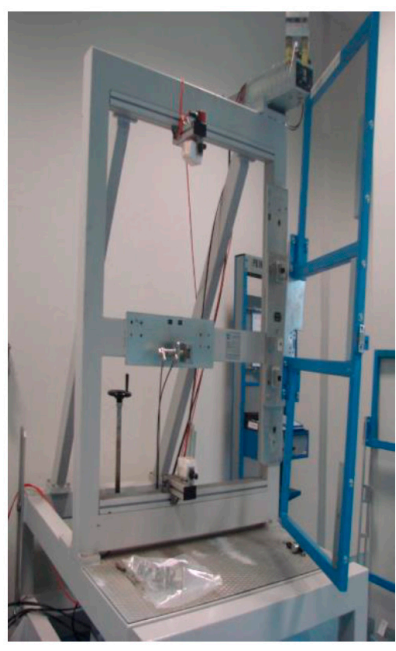

(b)

Figure 11. (a) View of Hinge strength test; (b) view of wind gust test.

With the durability test, the door is opened and closed 100,000 times in standard room conditions. No failure was observed in the hinge at the end of the test. Finally, the hinge is subjected to salt fog $(5 \% \mathrm{NaCl})$ for $96 \mathrm{~h}$. No visible corrosion is found. According to the tests, it is seen that FEA results are compatible with experimental results. In Table 4, results of tests and analyses are presented.

Table 4. Results of FEA and experiments.

\begin{tabular}{cccc}
\hline & FEA & Experiment & Requirement \\
\hline Hinge strength test & No break & No break & No break \\
Wind gust test & $2.7^{\circ}$ & $2.58^{\circ}$ & $\leq 5^{\circ}$ \\
Corrosion test & - & No corrosion detected & No corrosion detected \\
\hline
\end{tabular}




\section{Conclusions}

In this paper, a lightweight door hinge for sustainable commercial vehicles was designed and prototyped. Finite element analysis was used for development. The usage of aluminum alloys on door hinges of vehicles was investigated. To choose a proper aluminum alloy, several studies were conducted, taking into account safety regulations. After determining the suitable material with FEA, the validation of results was ensured via experiments. With the design study and content changing, the total weight of the hinge decreases by $65 \%$. The weight is $2.3 \mathrm{~kg} / \mathrm{per}$ hinge with steel material. When using Al7075 aluminum, it drops up to $0.72 \mathrm{~kg} / \mathrm{per}$ hinge. When taking into account the number of hinges in a commercial vehicle and the annual amount of production of commercial vehicles, tons of materials could be saved. Additionally, this lightweight hinge ensures a reduction of thousands of liters of fuel usage. Consequently, $\mathrm{CO}_{2}$ emission with thousands of kilograms could be decreased with this material substitution.

Due to its high specific strength, low density, and recyclability, it has been proven that Aluminum could be used instead of steel in door hinges of commercial vehicles.

Acknowledgments: The authors acknowledge the support of Turkish Technology and Science Minister under grant SAN-TEZ project 0635.STZ.2014 collaboration with Rollmech Automotive Company in Turkey.

Author Contributions: Mustafa Tüfekçi prepared an M.Sc. thesis and jointly prepared the paper with Fatih Karpat, who designed and implemented the manuscript. Mustafa Tüfekçi and Tufan Gürkan Yilmaz wrote the article. Mustafa Tüfekçi and Tufan Gürkan Yılmaz created the FEA and performed the bench tests. The authors discussed the results and commented on the manuscript at all stages.

Conflicts of Interest: The authors declare no conflict of interest.

\section{References}

1. U.S. Energy Information Administration, International Energy Outlook 2013. Available online: http://www. eia.gov/forecasts / ieo/pdf/0484(2013).pdf (accessed on 15 March 2014).

2. Uherek, E.; Halenka, T.; Borken-Kleefeld, J.; Balkanski, Y.; Berntsen, T.; Borrego, C.; Gauss, M.; Hoor, P.; Juda-Rezler, K.; Lelieveld, J.; et al. Transport impacts on atmosphere and climate: Land transport. Atmos. Environ. 2010, 11, 4772-4816. [CrossRef]

3. Helms, H.; Lambrecht, U. The potential contribution of light-weighting to reduce transport energy consumption. Int. J. LCA Case Stud. Light-Weight. Veh. 2006, 12, 58-64. [CrossRef]

4. Ungureanu, C.A.; Das, S.; Jawahir, I.S. Life-cycle cost analysis: Aluminum versus steel in passenger cars. In Proceedings of the TMS Conference, Orlando, FL, USA, 25 February 2007; pp. 11-24.

5. Kobayashi, S.; Plotkin, S.; Ribeiro, S.K. Energy efficiency technologies for road vehicles. Energy Effic. 2009, 2, 125-137. [CrossRef]

6. The European Aluminum Association (EAA). Sustainability of the European Aluminum Industry. Available online: http:/ / www.alueurope.eu/wpcontent/uploads/2011/08/Sustainability_Report_Sum.pdf (accessed on 1 March 2015).

7. Cheah, L.; Evans, C.; Bandivadekar, A.; Heywood, J. Factor of Two: Halving the Fuel Consumption of New U.S. Automobiles by 2035; Laboratory for Energy and Environment, Massachusetts Institute of Technology Publication: Cambridge, MA, USA, 2007.

8. Bandivadekar, A.; Bodek, K.; Cheah, L. On the Road in 2035: Reducing Transportation's Petroleum Consumption and GHG Emissions, Report Laboratory for Energy and the Environment; Report No. LFEE 2008-05 RP; Massachusetts Institute of Technology: Cambridge, MA, USA, 2008.

9. Tüfekçi, M. Hinge Modular Design, Optimization and Production Prototype for Light Commercial Vehicle Doors. Master's Thesis, Mechanical Engineering, Uludag University, Bursa, Turkey, 2013.

(C) 2017 by the authors. Licensee MDPI, Basel, Switzerland. This article is an open access article distributed under the terms and conditions of the Creative Commons Attribution (CC BY) license (http:/ / creativecommons.org/licenses/by/4.0/). 